\title{
Learning Assessment With Portofolio
}

\author{
Nurhasan \\ Student of Doctoral Program, Islamic University of Jakarta \\ Corespondent: hasan2134@gmail.com
}

Submitted : June 28,2020 Revised : July 15, 2020 Published : July 30, 2020

\begin{abstract}
To find out the competencies a person has, we need a tool called evaluation. There are two things that need to be distinguished in evaluation, the meaning is measurement and assessment or interpretation. To be able to measure correctly, you need the correct measurement tool too. The correct measuring device must meet several requirements, including: valid,reliable, and practical. There are several types of measuring devices. In addition there are subjective measurement tools (essays), objectives (multiple choice, matchmaking, short content, and right-wrong), and performance, now it is beginning to be known as portfolio measurement tools. The portfolio is a collection of the work of a student as a result of carrying out a performance task, which is determined by the teacher or by students with the teacher, as part of an effort to achieve learning goals, or achieve competencies specified in the curriculum.
\end{abstract}

Keyword: Learning, Assessment, Portofolio

\section{INTRODUCTION}

In education, the following three things must be mastered by a teacher, namely the curriculum, learning process, and assessment system (Surapranata and Hatta, 2006: 1), and all three must be mastered in a balanced manner. Weak in one thing, also weak as a professional teacher, with the result of failing to achieve the expected outputs and outcomes. Very well-versed about the curriculum, also very well-versed about the learning process, but weak understanding in the assessment, fatal for students because the "value" for students is "fate" for him.

One teacher assesses that it means imposing an undue verdict on their students. Conversely, fear of judging the way it is also imposed a bad verdict on them, nor does it give a true picture to users of graduates (users, stakeholders). Competence means "knowledge, skills and basic values that are reflected in the habits of thinking and acting". "Whereas the habit of thinking and acting that is carried out consistently and continuously enables a person to be competent, in the sense of having the knowledge, skills and values to do something" (KBK, 2002 via Soewandi, 2002).

In the education system whose vision is to realize competent people, it is known, inter alia, the term basic competencies, and indicators of learning outcomes, and strived to be achieved through accountable planned (responsible) learning programs. In the previous curriculum (Curriculum 1994), the two terms can be compared to the general learning objectives of a topic (subject matter, subject matter), and specific learning objectives of a topic. If we want to succeed in learning, indeed both types of competencies must be achieved. Because the goal is to achieve competence, not to master the learning material, then the material that must be studied is not always as much as substantial material from a subject, material must be chosen that truly functions to achieve the competencies set at a particular educational level. 
To find out whether competency is achieved, we need a tool called evaluation. In evaluating these two things, distinguishing between measurement and evaluation or interpretation, or these two activities: measuring and evaluating. Measurements occur when a teacher with the questions he made, or assignments that are asked to ask students to work on the problem, then correct it, and give a score on the work of their students.

To be able to measure correctly, you need the correct measurement tool too. The correct measuring instrument must meet the requirements: 1. Valid 2. reliable,3. practical. In the document Competency-Based Curriculum: Class-Based Assessment (Puskur, 2000), even other requirements are added about good assessments in addition to valid, steady, and practical, are: (1) Competency oriented; (2) Fair and objective; (3) Open; (4) Continuity; (5) Comprehensive; (6) Meaningful (easy to understand and can be followed up by interested parties).

Sumarna Surapranata and Muhammad Hatta (2004: 7-12) still added by providing motivation and education, with the intention that when a student reaches a certain level of competency achievement, he is motivated to achieve more competence. The measurement results are in the form of a score, for example, a score of 55, 64, 49, 79, 56, or 67 . This score has no meaning before being interpreted, for example interpreted as passing, or not passing, or given a letter value $\mathrm{A}$, or $\mathrm{B}$, or $\mathrm{C}$. To be able to interpret a score needs to be benchmarked.

\section{METHOD}

There are internal standards, and external standards. the form of standards set after the competence achieved by the class is known, whereas criteria for criteria are determined before the state of the class is known. The choice of which standard depends on the vision and mission of the educational institution, or on the mandate of the curriculum. The 2004 curriculum and the Education Unit Level Curriculum (KTSP) mandate the application of assessments based on criteria, not norms.

With this basis, the mastery learning approach is implemented, which is a learning approach that requires students to reach certain competency qualification limits. (Based on KTSP, each level of education can set a certain level of achievement for students, for example, the achievement of $56 \%$ of the competencies that should be achieved, or $60 \%$, or $65 \%$, even $70 \%$, even given the freedom for teachers in the education unit to set a policy of completeness limits in stages from semester to semester for the subjects they support).

In addition there are subjective measurement tools (essays), objectives (multiple choice, matchmaking, short content, and right-wrong), and performance, now it is beginning to be known as portfolio measurement tools. Although in the Republic of Indonesia's Minister of National Education Regulation, Number 20, 2007, portfolio assessment standards are not explicitly mentioned as one of the measurement tools for assessment, they are not denied for use in evaluating both the process and learning products due to the various advantages possessed by this type of assessment. Moreover, this type of portfolio assessment by the government was determined as the only teacher certification tool. Therefore, the following is briefly discussed: (1) Why portfolio valuation is applied; (2) What is the nature of the assessment with the portfolio; (3) How to arrange a portfolio and what it looks like. 


\section{RESULT AND DISCUSSION WHY IS THE ASSESSMENT WITH PORTFOLIO?}

The following four sources provide confirmation of the need to establish an assessment policy with portfolios, in addition to other assessments. In his study of assessment practices in the field, the Curriculum Center (2000) found that classroom assessment practices did not use more varied methods and tools. Including the assessed aspects, they still emphasize cognitive aspects, with little psychomotor, and almost no touch on the affective aspects of evaluation, and that too is not yet at a high cognitive level.

From the policy makers, such a reality, of course, is seen as detrimental to students. That is why a policy called class-based assessment (PBK) was issued, with the aim that there would be a balanced assessment of the three psychological domains, using various forms and models of assessment formally and informally, and on an ongoing basis (Puskur, 2000). The policy set out in the PBK also mandates that: (1) What is assessed is competence (not material); (2) Done with: Written test, Act test, Giving assignments, Project Appraisal, Product Rating, Attitude assessment, and Portfolio assessment (Surapranata and Hatta, 2006: 18-21).

So whatever type of assessment must allow the best opportunity for students to show what they know and understand, and demonstrate their abilities. From this policy began to be introduced assessment with the portfolio. In the Specific Portfolio Development Guidelines document for Assessment, the 2004 High School Curriculum (MONE, 2004: 2) noted six problems related to the assessment of learning outcomes that led to assessment with portfolios as stated below:

1. Standardized tests usually don't assess students' ability to solve problems broadly.

2. Closed tests (tests with single answers) do not provide an adequate description of students' abilities.

3. Assessment is not adjusted to the way students learn which usually varies.

4. Assessment does not provide an opportunity for students to show their abilities, not their inability.

5. Assessment does not consider student progress in certain subjects.

6. Assessment is not used as a way to improve learning.

Another source (Sinaradi in Suparno, 2001), mentions several reasons for applying the portfolio appraisal policy, including:

1. Until now all teachers have done is looking for mistakes, not student excellence, including assessments through the UUB, or the UN.

2. What is assessed is sectoral: only the cognitive domain, and a little psychomotor, whereas the ideal of education is the formation of a whole person.

3. Rating is only the result of a momentary recording, such as a momentary photograph.

In some countries, in fact, it was found that some teachers did not understand the assessment in depth because most teachers did not have a formal educational background specifically in the assessment of education (Surapranata and Hatta, 2004: 70). In the PBK, authentic assessment is also applied, namely: (1) Assessments that involve students realistically in assessing their own achievements; (2) Performance-based, realistic, and teaching-based assessments; and (3) Assessment contains information or data collected from various sources, through various methods, and through various time points. One effective authentic assessment is assessment with portfolios (Surapranata and Hatta 2004: 71). 


\section{WHAT IS THE ASSESSMENT WITH THE PORTFOLIO?}

General words, after being used in certain scientific fields, are given certain contents (meanings). Therefore, there arises what are called terms, or technical words (technical terms). The word portfolio is a common word too. However, in certain scientific fields the general word is given a certain meaning as well. For example the word green table. In the field of law, the green table is given the meaning 'court', whereas as a general word it means 'green table'. The original meaning of a portfolio is a kind of folder, box, or bag that is flexible for use in carrying loose letters or documents, pictures, or loose pamphlets.

So, a portfolio in the form of a collection of someone's work in the form of a collection of documents freely. By looking at the collection, one can trace the history of achievement development or whatever he has achieved (Soewandi, 2005). In the corporate world, a portfolio is given the meaning of a collection of documents owned by a company and is used to assess the success of the process of achieving the goals of a program or production plan (Surapranata and Hatta, 2004: 26).

In the world of photographer portfolios are also given the meaning of a collection of documents that will be used to show prospective work to customers by showing the collection of work they have (Surapranata and Hatta, 2004: 30). In the world of health, a portfolio of documents is used to monitor the development of one's health. In the world of education, in general the portfolio also means a collection of documents, evidence that contains information about the ability and development of students from time to time (Surapranata and Hatta, 2004: 30). The notion of such a portfolio is adopted into the education system, and specifically adopted as one of the assessment tools, specifically for assessing: (1) Learning process; (2) Learning outcomes; and (3) Student learning processes and outcomes (Cole, Ryan, and Kick, 1995 via Surapranata and Hatta, 2004: 46; Ministry of National Education, 2004: 9).

It just needs to be noted that assessment of learning with portfolios should not exclude assessment by other means, for example, by tests, deeds, or others. However, not every collection of a student's work is called a portfolio. Portfolios "are only a collection of the work of a student as a result of carrying out a performance task, which is determined by the teacher or by students with the teacher, as part of an effort to achieve learning goals, or achieve competencies specified in the curriculum" (MONE, 2004: 3). It is also "focused on documents about productive student work, namely 'evidence' about what students can do, not what cannot be done, or cannot be answered, or cannot be solved by students" (Depdiknas,2004: 3).

The word 'document collection' in the definition must be interpreted 'documents that are arranged systematically and organized' (Surapranata and Hatta, 2004: 28); and the task completion time is limited, and only selected according to specified competencies. What works can be collected in a portfolio? The following examples are given: (1) The results of an inquiry project, or student practice that is presented in writing; (2) Students work using a recording device, or computer, or diskette; (3) Pictures or reports of observations; (3) Description and diagram of solving a problem; (4) Group work report; (5) Reports on student attitudes toward learning (MONE, 2004: 4); (6) Written award; and (7) The work in the form of writing, summary(Surapranata and Hatta, 2004: 39).

Specifically for language subjects, Sumarna Surapranata and Muhammad Hatta (2004: 36) provide examples of documents in the portfolio as follows: (1) Teacher observation notes about students' speaking abilities; (2) Student responses to stories / tales read by the teacher; (3) List and brief comments about the book you have read; (4) Synopsis of the reading made; (5) Letters made; 
(6) Text of speech; (7) Free writing (poetry, prose); (8) Visit report; (9) Writing in the wall magazine..

What is said above (and also below) is the ideal portfolio demands. Regarding this, the Ministry of National Education (2004: 6) cautions two weaknesses in using portfolios as an assessment:

1. The use of portfolios depends on the ability of students to convey their descriptions in writing. As long as students do not speak fluently, the use of portfolios is an additional burdensome burden.

2. For teachers, using portfolios as an assessment tool requires a lot of time to do scoring, especially if the class is large.

Sumarna Surapranata and Muhammad Hatta (2004: 73-74, 90-96), in fact, mentioned several weaknesses, among others, as follows:

1. In some countries many teachers have difficulty because of the habit of teachers who give tests in assessment, and this habit is ingrained. (It seems that this situation also applies to most teachers in Indonesia. Additionally, it is still doubtful whether they really understand the nature of the test, how to arrange the correct test, and how to assess the test results).

2. Teachers need extra time to plan and carry out assessments with portfolios.

3. Assessments with portfolios are less reliable compared to assessments that use daily tests, general tests or national examinations that use tests; let alone self-assessment as recommended in the portfolio.

4. The teacher has a tendency to pay attention only to the final achievements. If this happens, it means that the assessment process does not get proper attention.

5. Teachers and students are usually trapped in an atmosphere of top-down relationships: teachers know everything and students need to be told. If so, the initiative and creativity of students does not develop, even though assessment with a portfolio requires both.

6. There is an element of skepticism, especially parents, because so far the success of their children is only based on the final test score, rankings, and quantitative matters. Whereas valuation with a portfolio requires the opposite, that is, valuations are not numbers. For teachers, assessment is not a number is not easy work.

7. Assessment with a portfolio requires adequate document storage, especially if the number of students is large enough. That is why, the Ministry of National Education (2004: 6) suggests: "... the portfolio assigned to be made needs to be adjusted to the ability of students in Indonesian written language and the time available for teachers to read".

\section{HOW TO DEVELOP PORTFOLIO AND WHAT LIKE THE PORTFOLIO FORM?}

Ministry of National Education (2004: 8-10) in the Special Portfolio Development Guidelines for Assessment document mentions the following six steps in developing a portfolio.

Step One: Determine the Purpose or Focus of the Portfolio In this step the teacher does the activity :

1. Determine the purpose of assessment with the portfolio: whether to monitor the learning process (process oriented), or evaluate learning outcomes (product oriented), or both.

2. Determine what assessment with the portfolio is used: whether to show the learning process to parents, or assessment at the end of learning, or at the end of the level of education.

3. Determine the relevance (link) between the Documents and the objectives (competencies) to be assessed: needs to be determined whether there is a self-assessment, audio, essay, whether it can be done together (in groups). 
4. Determine how many Documents in the portfolio will be used as assessment material.

5. Determine the competencies (standards, basics, and indicators) what they are trying to achieve with the portfolio.

6. Determine the Documents collected: whether only the best work, or its growth or development, or both.

7. Determine whether the portfolio will be used for formative, or summative assessment, or both. Note: There are examples used in Australia. In The Student Need Assessment Procedures the portfolio is decided for formative and summative assessment of the ability of students to speak and write in English. Contents: Oral: Two samples taken from: 1. retelling a story 2. reporting on a process 3. giving an opinion Written: Three samples taken from: 1. a recount 2. an argument 3. a narrative or a report (Surapranata and Hatta, 2004: 106).

8. Determine who determines the contents of the portfolio: whether only the teacher, the teacher and students, or other parties (such as parents).

Step Two: Determine the Content Aspect In this step the teacher does the activity:

1. Determine only the best work of students, or works that contain the development of learning.

2. Determine what knowledge, skills, or attitudes are the main aspects to be assessed. Note: So, not every basic competency is the contents of the portfolio.

3. Determine the number of Documents to be used as material for assessment.

Step Three: Determine the Form, Arrangement, or Organization of the Portfolio (see also Surapranata and Hatta, 2004: 30-38) In this step the teacher carries out activities:

1. Determine the shape of the portfolio. Note: Generally portfolio forms consist of (a) a list of document contents, (b) document contents, (c) boundaries (restrictions) for each document (for example with colored paper as a boundary), and (d) notes for teachers and parents.

2. Determine the type of content of the document, that is, determine the basic competencies and indicators of what must be achieved in the form of documents (which may be copyrighted works or report notes, or others)

3. Provide notes / comments / grades on each Document by teacher / parent Note: Examples of teacher and parent comments below are taken from Sumarna Surapranata and Muhammad Hatta (2004: 38).

Examples of Teacher and Parent Comments on Assessment Results with Portfolios

\begin{tabular}{|l|l|}
\hline \multicolumn{2}{|c|}{ Class 3 Islamic Religion Portfolio Assessment } \\
\hline $\begin{array}{l}\text { Basic Competence: Tells the events of natural } \\
\text { disasters that often occur }\end{array}$ & $\begin{array}{l}\text { Student name: Lilis } \\
\text { Date: 9 September 2019 }\end{array}$ \\
\hline
\end{tabular}

\begin{tabular}{|c|c|c|c|c|c|}
\hline Indicator & \multicolumn{5}{|c|}{ ASSESSMENT } \\
\hline \multirow{2}{*}{$\begin{array}{l}\text { - Explain natural disasters that occur } \\
\text { around } \\
\text { - Explain the contents of the series } \\
\text { drawings about natural disasters that } \\
\text { occur around } \\
\text { - Provide feedback and suggestions on }\end{array}$} & Very Bad & $\mathrm{Bad}$ & Medium & Good & Vey Good \\
\hline & & & & & \\
\hline Achieved through: & Teacher's & ment: & & & \\
\hline
\end{tabular}




\begin{tabular}{|l|l|}
\hline $\begin{array}{l}\text { - teacher's help } \\
\text { - whole class } \\
\text { - small groups } \\
\text { - alone }\end{array}$ & $\begin{array}{l}\text { Lilis was still not very good at explaining and was less able } \\
\text { to provide responses and suggestions for her writing. }\end{array}$ \\
\hline \multicolumn{2}{|l|}{ Parental comment: Lilis still needs a lot of practice. But these results are quite satisfying parents } \\
\hline
\end{tabular}

4. Determine what should be in the table of contents of the portfolio.

5. Determine the definition of each category or type of document content unit.

Step Four: Determine the Use of Portfolios In this step the teacher carries out activities:

1. Determine its use: is it for students only, or only parents, or school principals, other teachers, and other students.

2. Determine the weighting of the portfolio value to other assessment components in the context of determining the final value / report card.

Step Five: Determine How to Assess the Portfolio In this step the teacher carries out activities:

1. Determine scoring guidelines (rubrics) for each portfolio

2. Determine the assessment by the teacher himself or the teacher and students

3. Determine the making of a rubric (detailed assessment guidelines) in advance to determine the assessment of the portfolio; (assessment should not only be based on success, but also on the process). That is why, the criteria that should be used:

a. proof of the process

b. quality of activities: whether shows increased knowledge, skills, attitudes, and involves some basic material, or not,

c. diversity of approaches used

Step Six: Determine the Form or Use of the Rubric (MoNE, 2004: 10) In this step it is determined whether the portfolio value will be expressed as just one score in the overall assessment, or not. To assign students to make a portfolio, the teacher makes the following preparations:

1. Determine the purpose of the portfolio: the teacher determines whether to assess the best work, or assess student progress

2. Adapt the task to the curriculum, or adjust the task to the objectives of the subject (competencies and indicators)

3. Determine indications: the teacher determines what items must be contained in the portfolio

4. Determine the portfolio format

5. Determining quantity restrictions, meaning that the length of the portfolio needs to be limited so it does not become a burden on the teacher

6. Determine the rubric (scoring guidelines) Specifically determining the rubric of the assessment can be selected verbal criteria, for example, not good - good - very good; or very bad - bad medium - good - very good; or with numbers. The level of value specified depends on whether or not it is met, or at least the requirements that are met: the more complete, the higher the level of value.

Examples of verbal assessment can be opened again on the page in advance, or in Sumarna Surapranata and Muhammad Hatta (2004: 127). Following are examples of assessments with figures taken also from Sumarna Surapranata and Muhammad Hatta (2004: 144). 
Example Rating with Numbers

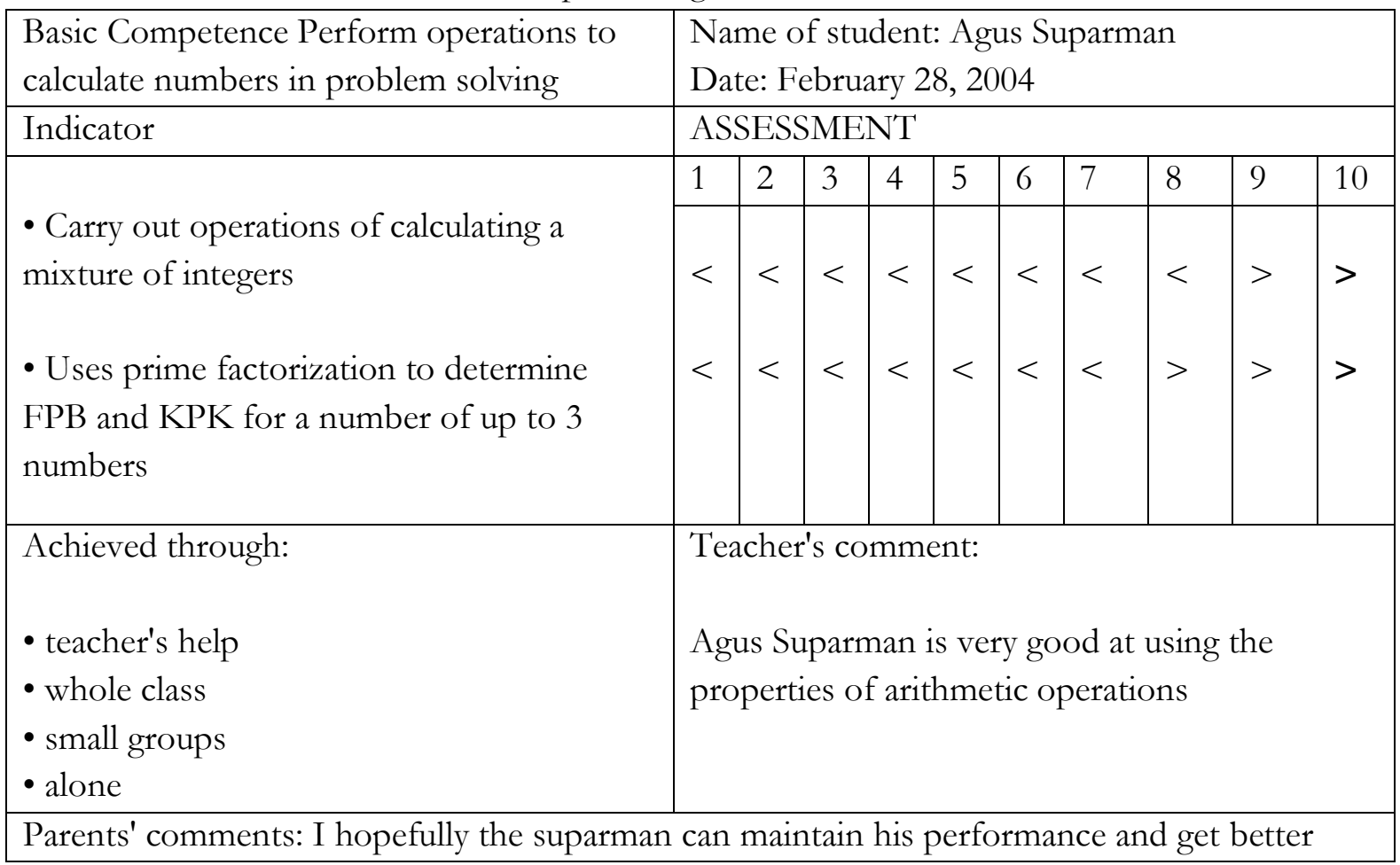

\section{CONCLUSION}

It is equally important to remember once again that not every competency (standard, basis, and indicator) can be realized with documents in the form of performance. So, not every competency can be assessed with a portfolio.

\section{REFERENCE}

In P. Suparno, et al. (peny.). (2001). Towards Active Learning. Yogyakarta: USD Issuance.

KBK One Day Seminar on Socialization for FKIP lecturers, USD, 4 December. 2005. "Competency Based Curriculum: Class Based Assessment".

Kompas.Sinaradi, F. (2001). "Method of Assessment of Student Learning Outcomes with Portfolios".

Ministry of National Education. Curriculum (2004). Specific Portfolio Development Guidelines for Assessment.

Paper submitted to elementary, middle and high school YPKK KMS teachers in Sorong Region, Papua, August 8-11. 2005. "Learning Assessment with Portfolios".

Paper presented to Catholic High School teachers in Taruna Jaya, Sampit, Central Kalimantan, November 28-30.

Rina, Tri Kartika. (2002). Portfolio Assessment.

Soewandi, A.M. Slamet. (2002). Competency Based Curriculum.

Surapranata, Sumarna, \& Muhammad Hatta (2006). Portfolio Assessment: Curriculum Implementation 2004. Bandung: PT Remaja Rosdakarya. 